\title{
EDITORIAL
}

\section{¿Para qué RETLA?}

\section{For what RETLA?}

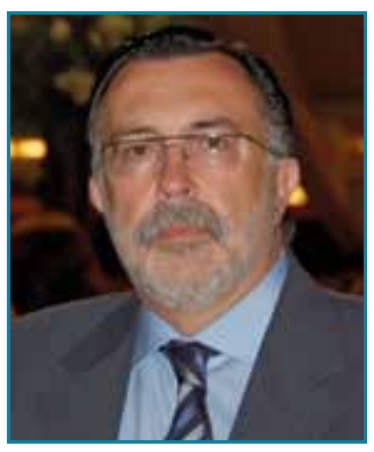

Dr. Luis A. García-Lomas Pico Senador de la SETLA
A gradezco de corazón la amable invitación de nuestro presidente el Dr. Vaquero Ruipérez para volcar en este editorial del quinto número de RETLA algunas reflexiones que quisiera compartir con todos vosotros.

En el transcurso de mi presidencia, la Junta Directiva de SETLA acordó poner en marcha la Revista Española de Traumatología Laboral y, pese a habernos puesto a esa labor, los proyectos muchas veces se alargan más de lo deseable, de modo que el primer número de RETLA vio la luz en la presidencia del Dr. García Berlinches, gracias al esfuerzo continuado de su Junta y especialmente de los Dres. Sánchez Alepuz y Aguilera Repiso.

En cualquier caso, RETLA es el fruto del esfuerzo de la familia de SETLA.

Me pregunto en el título: ¿para qué RETLA? ¿No debería preguntarme por qué RETLA? Tras una reflexión, decidí enunciar la primera pregunta porque desde el punto de vista humanista ofrece un planteamiento de motivación, excluyendo del razonamiento cualquier personalismo.

¿Para qué nos planteamos impulsar una revista científica en un mundo en el que la cifra de publicaciones científicas es enorme? En 2018, y según datos del Banco Mundial, se publicaron 2,55 millones de artículos científicos y técnicos. ¿No parece fútil zambullirse en ese mar de tinta y papel (o de bits)? ¿Para qué debemos hacerlo? ¿Debemos perseverar en el intento?

Una revista científica es el garante de la calidad de aquello que recoge en su publicación y los mejores garantes de una línea determinada de conocimiento son la gente con amplia experiencia en el sector específico que gestiona dicho

https://doi.org/10.24129/j.retla.03105.fs2005002

FS $@ 2020$ Sociedad Española de Traumatología Laboral. Publicado por Imaidea Interactiva en FONDOSCIENCE ${ }^{\circledR}$ (www.fondoscience.com). Este es un artículo Open Access bajo la licencia CC BY-NC-ND (www.creativecommons.org/licenses/by-nc-nd/4.0/). 
conocimiento. Las revistas de gran prestigio internacional están avaladas por sus comités editoriales plagados de profesionales con amplio reconocimiento en el mundo científico en general, pero muy especialmente en el sector específico del conocimiento al que se destina la publicación, que velan por la calidad de la información y mantienen el prestigio de la revista. Este prestigio la transforma en objeto de deseo para quien quiere publicar y en obligada consulta para quien quiere progresar.

La traumatología laboral española es una disciplina diferenciada del tronco común de la traumatología y la cirugía ortopédica, y tiene sus peculiaridades propias. Esta circunstancia es prácticamente exclusiva de nuestro país. Nuestra peculiaridad no podía seguir ignorándose. Teníamos que dar posibilidad a todos los que trabajan en este campo de disfrutar de una herramienta de calidad, ajustada a la idiosincrasia de la traumatología laboral, con garantes de nuestro propio sector a la hora de visar los contenidos y abrir un terreno de expresión y de diseminación del conocimiento en el lenguaje particular de nuestra disciplina.

De la participación de los profesionales de nuestro entorno y de la tutela y garantía de algunos de los más prestigiosos, surge la posibilidad de hacer que RETLA ocupe un lugar en ese universo de las publicaciones científicas. Pero, además, nuestro carácter pluriacadémico nos facilita la intercomunicación científica entre todas las especialidades inmersas en este territorio: traumatólogos, médicos asistenciales, enfermeros, fisioterapeutas, terapeutas ocupacionales, psicólogos, especialistas del dolor, etc.

Por eso nos tiramos al agua y, tras la zambullida, estamos a flote y con mucha fuerza para nadar y recorrer camino. Aquí, en este punto, si empujamos todos alcanzaremos el siguiente paso: incorporar y favorecer el intercambio de conocimiento en RETLA de otros profesionales que puedan aportar su saber al nuestro.

Por eso hay que perseverar en lo iniciado y debemos hacerlo porque tenemos mucho que enseñar y mucho que aprender, y porque, en palabras del rey del blues B. B. King: "The beautiful thing about learning is that no one can take it away from you" ("lo maravilloso de aprender algo es que nadie puede arrebatárnoslo').

No puedo despedirme de vosotros, en estos momentos de tanta dureza humana y profesional, sin declarar sin sonrojo que soy un ser afortunado porque pertenezco a un grupo de personas, los profesionales sanitarios, que en su enorme diversidad individual han demostrado que saben trabajar juntos en una sola dirección siempre que alguien sufre, a costa de mucho (a veces, la propia vida). Permitidme que os envíe desde aquí a todos un enorme abrazo y mi admiración. Luis A. García-Lomas Pico
Senador de la SETLA 